ful into the mouth and stimulating the act of swallow. ing by pressing on the back of the tongue. In the later stages of the disease, when the patient had well marked trismus for some time, the act of feeding was accomplished with great difficulty.

After August 1, the fourteenth day, she began to emaciate very rapidly and contractures took place in many groups of muscles, beginning in the left arm, which was held in a position of over-extension and extreme pronation; the elbow could be bent only with the greatest difficulty.

Trismus and opisthotonos became more marked, the legs were gradually drawn up to the body and resisted all but the strongest efforts to straighten the knees, the hip joints never quite yielded to the efforts to straighten the thighs. Such attempts to straighten the limbs caused an expression of pain to pass over the patient's face and were evidently felt. The right arm did not become so completely rigid as the left. When the temperature dropped on the thirty-third day the patient became brighter, she would follow a movement with the eyes a little and would lie with her eyes open longer at a time.

From the thirty-sixth to the forty-third day there was again a slight rise of temperature for a few days; during this time she became brighter every day. She began to talk on the thirty-seventh day, at first only in monosyllables. On the forty-second day she put a sentence together. At this time she became very much excited, singing and chattering continually. After September 1 she calmed down and gradually began to recognize her friends and to call them by name, but she did not swallow of her own accord nor did she recognize the calls to urination and defecation until September 7.

The muscular rigidity and contractures passed off in the order in which they had come on. First, she began to move the head, then the neck, the right arm, the left and later the legs. It was several weeks before the muscular symptoms entirely disappeared.

As to the treatment: At first leeches and blisters were placed behind the ears and on the back of the neck. On July 19 the iodid of potassium was administered, beginning with five grains every two hours, increasing the dose gradually until July 31 , when she was taking 25 grains every two hours or 300 grains a day. As symptoms of iodism began to present themselves the dose was rapidly decreased to 120 grains per day and the tinct. digitalis 2 minims every four hours, given with the iodid. Strychnin was given for about one week, but was stopped as the tetanic symptoms seemed to increase. August 20 the sodium iodid was substituted for the potassium, and strophanthus for digitalis. The iodid was given in 20 grain doses three times a day, with the addition of $2 \mathrm{~min}$ ims of the strophanthus.

The question of diagnosis in this case was one not easily answered by those who saw the case regularly or who saw it in consultation occasionally. As the meningeal symptoms became more marked, the low and often subnormal temperature suggested tubercular meningitis, particularly because the attack followed measles.

The complete recovery without any permanent paralytic symptoms contradicts such a theory. The muscular tremors, tetanic symptoms, the contractures, the unconsciousness and the irregular fever are sim. ilar to the symptoms noted by other observers and justified us in considering the case as one of cerebrospinal meningitis.

\section{HYSTERIA IN CHILDREN.}

resented to the Section on Diseases of Children, at the Forty-eighth Annual Meeting of the American Medical Association, held at Philadelphia, Pa., June 1-4, 1887.

BY CHARLES W. BURR, M.D.

PHILADELPHIA, PA.

The time is so short and the program so full of more important matter that I shall detain you but a little and, not attempting to be at all exhaustive, will simply sketch the histories of a few cases. This is my only excuse for offering a paper purely clinical and of value only in recalling to you the fact that hysteria is not a disease of women or adults alone, but may occur at any age and in either sex.

The first patient had pseudo-Pott's disease. She was 9 years of age, with nothing significant in her previous personal or family history. For some time before I saw her she had complained of pain along the spine, worse in shifting spots, coming on in attacks, and sometimes so severe as to cause long continued spells of weeping. The spine became slightly curved laterally and she walked with a limp and complained of great weakness in the legs at times. On examination she was found to be a fairly well nourished but distinctly neurotic child. There was apparently severe pain on light pressure over the spine, the point of greatest pain varying greatly from time to time, but if the pressure was increased, and at the same time the child's attention attracted to something else, all signs of pain disappeared. There was slight apparent lateral curvature, but it was only apparent, not real, due to attitude and nothing more. There was no rigidity of the muscles of the back either at rest or during movement. She walked with a slight limp and complained that her legs were weak and painful, but she rose from the ground without difficulty. The knee-jerks were normal. There was no anesthesia, no muscular wasting, no palsy of the bladder or rectum. Temperature remained normal. Vision was good and there was neither contraction nor reversal of the fields of vision. In this case the mimicry of caries of the spine by hysteria was so superficial that diagnosis was not difficult. Separation of the child from her family, strict confinement in bed and hospital control soon cured the attack.

Another child, A. B., female, 10 years old, had never had any serious illness, but had always been nervous, supersensitive and mentally too active. In January, 1894, she had an attack of influenza, from which she recovered completely, but during convalescence a hard, barking cough began. After a féw days, the cough continuing and no fever having developed, she suddenly became delirious, saw visions of ugly men whom she talked to and about, showed horror and fear, seemed not to know her parents and became very dramatic. The attack lasted for several hours and recurred several times during the next two weeks. She was then brought to me and examination revealed the following condition: She was a healthylooking, well developed child. Every few moments there was a long deep inspiration followed by a sudden explosive expiration, which by some use of the imagination might have been said to have resembled a bark. If the attention were occupied it ceased, but only for a time. It was not willed. It ceased during sleep, but often prevented sleep for hours. There were also irregular, choreiform, half purposive shrugging movements of the shoulders, and the facial muscles of expression were in constant action. The heart 
and lungs were normal and the general nutrition good. The fields of vision were normal, the reflexes present and there was no anesthesia. Under treatment she soon recovered.

A girl 11 years of age presented an interesting combination of hysteria and organic joint disease. During convalescence from typhoid fever and after the temperature had permanently fallen to the normal, she began to complain of pain in both hips. Soon she ceased to move the legs and they became rigidly flexed upon the abdomen. On examination I found a stout, well nourished, bright and too sedate child. She was bedridden. The legs were flexed upon the thighs, the thighs upon the abdomen, and the knees pressed strongly against each other. No force permissible could overcome the contractures. All attempts at passive movement caused extreme pain. The patient could not move the legs at all. Sensation was normal. There was no atrophy. The knee-jerks could not be obtained, probably not because they were absent but on account of the contractures. There was no palsy of the bladder or rectum and no change in the fields of vision. Under ether all the contractures except that of the right hip relaxed, returning, however, with returning consciousness. It had been a question whether there was distinct organic joint disease, or whether it was all hysteria, or a mixture of both. The result solved the problem. All the contractures save that of the right hip rapidly passed away, and careful surgical examination proved there the existence of organic trouble. Doubtless this organic disease acted as an unconscious suggestion and so caused the hysteric outbreak.

Another case of hysteric contracture occurred in a girl 7 years of age. She has always been neurotic, selfish and unmanageable, and is the daughter of an hysteric mother and an overworked and unsuccessful father. One day, after a scolding, she said she could not walk because she could not put the right foot to the ground, but only the toes. The scared mother thought of course of palsy and petted where she had before abused, and the trouble became still worse. I saw the child a few days later. There was marked. apparent spasmodic clubfoot. She stood upon the toes and outer side of the right foot, the heel being drawn up from the ground and the muscles of the calf in rigid spasm. There were no other physical signs. Hysteria alone explains the case. No organic disease can cuuse a sudden clubfoot, without palsy, increased reflexes, muscular wasting, change in the electric reactions or alterations of sensibility. Medical neglect cured the patient in a few days.

More serious than any of the above is a case now under observation in which the question, still unsolved, is whether there is hysteria alone or complicating a tumor of the brain. A girl, 10 years old, several months ago had some acute fever from which she recovered in a few weeks. A short time afterward she began to complain of severe diffuse headache, constant and preventing sleep, and attacks of vomiting immediately or almost immediately after eating. A few weeks ago she suddenly became violent, seemed to have visual hallucinations, talked about seeing people and about men trying to murder her. The attack lasted a day and has not recurred. Later she began to stagger in walking, said her legs were weak, and finally could not walk at all. The amount of weakness in the legs has varied greatly, she sometimes being able to walk. On examination I found a well nour- ished, bright child. While in bed she could move the legs well, without palsy and without ataxia, but as soon as she attempted to stand both appeared. The knee-jerks were normal. There was neither wasting nor anesthesia. The bladder and rectum were under complete control. Examination of the thoracic and abdominal organs was negative. The urine contained neither albumin, sugar nor casts. After sending her to the hospital, headache and vomiting ceased almost immediately and in a few days she could walk some, though she still staggered very much and could not stand at all with the feet close together. The palsy and ataxia varied much from day to day. This complex of symptoms might be hysteric, but ophthalmoscopic examination showed suspicious signs of a beginning optic neuritis, and a cerebellar tumor would also explain the case. The diagnosis must await events.

These cases, all too hastily sketched and leaving much of importance undescribed, are of interest as examples of hysteria in childhood. They show well the power of acute organic nervous or non-nervous disease in precipitating an hysteric outburst and the occasional impossibility of differential diagnosis between organic brain disease and hysteria. They illustrate the power of treatment, a subject too well known to need detailed attention. I have used the word cure several times. I wish it to be understood to refer only to the specific attack and not to the inherited predisposition. We usually cure not the hysteria but the attack. Hysteria in children, even when apparently transient and trifling, is in reality very serious, for it signifies inherent and often inherited nervous instability. These children need not only treatment for the attack, but most careful education of the will and the emotions, to save them in the future from suffering from hysteria.

\section{SOME CAUSES OF CONGENITAL DEFORMITIES.}

Presented to the Section on Diseases of Children, at the Forty-eighth Annual Meeting of the American Medical Association at Philadelphia, Pa., June 1-4, 1897.

BY ELLA E. BARNES, M.D. JIRMINGHAM, ALA.

"As pliant twig by fair and careful bending, In perfect trunk of future tree will show, So in this life of Fate's mysterious sending, Our ends by our beginnings we shall know.'

More attention is given each year to preventive measures against disease, and we who stand on the watch-towers guarding humanity, have a right to inquire into the origin of these little charges; we are allowed to "go behind the boards" and investigate the cause of the defects.

We find anomalies much less frequent in animals than in man, and less common in the negro race than in the white.

There is a vast amount of superstitious material concerning maternal impressions. Here are specimens of such "old folk lore." One woman, two and a half months pregnant, goes to the kitchen, and in searching for a match in the darkness, puts her hand on a fish that her husband has brought home for breakfast. When her babe comes it is afflicted with ichthyosis. Another is terrified by a man in a state of inebriety staggering into her room, with the result of an idiotic offspring. Another attends the circus and menagerie with an alleged result of a dog-faced 